\title{
PENGARUH GAYA KEPEMIMPINAN TRANSFORMASIONAL TERHADAP INTENTION TO QUIT DIMEDIASI OLEH KEPUASAN KERJA PADA KARYAWAN
}

\author{
Putu Wahyu Yana Prasetya ${ }^{1}$ \\ I Gusti Ayu Manuati Dewi ${ }^{2}$
}

\author{
${ }^{1,2}$ Fakultas Ekonomi dan Bisnis Universitas Udayana (Unud), Bali, Indonesia \\ E-mail:yana121297@gmail.com
}

\begin{abstract}
ABSTRAK
Penelitian ini bertujuan untuk menguji pengaruh peran mediasi kepuasan kerja pada pengaruh gaya kepemimpinan transformasional terhadap intention to quit. Penelitian ini dilakukan terhadap karyawan PT. Visionet Data Internasional Service Point Denpasar, Bali. Populasi dalam penelitian ini sebanyak 48 orang dengan menggunakan sampel jenuh ditentukan sampel sebanyak 48 orang. Metode pengumpulan data dilakukan dengan kuesioner. Teknik analisis data yang digunakan adalah Analisis CFA, Uji Asumsi Klasik dan Analisis Jalur. Hasil penelitian menunjukkan bahwa variabel gaya kepemimpinan transformasional tidak berpengaruh terhadap intention to quit, gaya kepemimpinan transformasional berpengaruh positif dan signifikan terhadap kepuasan kerja, kepuasan kerja berpengaruh negatif dan signifikan terhadap intention to quit, kepuasan kerja memiliki peran mediasi dalam pengaruh negatif dan signifikan gaya kepemimpinan transformasional terhadap intention to quit. Jadi semakin tinggi gaya kepemimpinan trasnformasional, makasemakin tinggi pula kepuasan kerja dan tingkat intention to quit karyawan akan menjadi semakin rendah.
\end{abstract}

Kata Kunci: gaya kepemimpinan transformasional, kepuasan kerja, intention to quit

\begin{abstract}
The research aims to examine the effect of transformational leadership style on intention to quit mediated by job satisfaction. This research was conducted on employees at PT. Visionet Data Internasional Service Point Denpasar, Bali. The population contained in this study were 48 and by using saturated samples there were 48 respondents. The method of data collection is done by questionnaire. Data analysis techniques used are Factor Analysis, Classical Assumption Test and Path Analysis. The results showed that transformational leadership style variables had no negative and significant effect on intention to quit, transformational leadership style had a positive and significant effect on job satisfaction, job satisfaction had a negative and significant effect on intention to quit, job satisfaction had a mediating role in a negative and significant influence transformational leadership style towards intention to quit So the higher the transformational leadership style and job satisfaction in the company will be able to reduce the level of intention to quit employees.
\end{abstract}

Keywords: transformational leadership style, job satisfaction, intention to quit 


\section{PENDAHULUAN}

Perusahaan yang terdapat di Indonesia, saat ini memiliki beragam jenis usaha dan tujuan masing-masing serta terus berusaha untuk menjaga kelangsungan hidup dengan cara mengembangkan kegiatan usahanya. Salah satu tujuan perusahaan adalah untuk memperoleh keuntungan atau laba dari kegiatan usahanya. Perusahaan sangat bergantung pada peran sumber daya manusia (SDM), karena SDM yang ada akan menentukan keberhasilan perusahaan dalam mengembangkan usaha dan mencapai tujuannya. Dengan demikian, perusahaan harus mampu mempertahankan SDM yang sudah dimilikinya saat ini.

Social exchange theory (teori pertukaran sosial) menyatakan bahwa jika karyawan memahami bahwa perusahaan tempatnya bekerja telah memenuhi kebutuhan mereka, maka mereka pun akan meningkatkan kinerja dan menunjukkan nilai-nilai perilaku, serta sikap yang diinginkan perusahaan (Jauhar dkk., 2017). Sejauh mana karyawan percaya bahwa perusahaan telah menghargai perilaku dan kerja keras mereka, akan memiliki dampak yang kuat pada kontribusi karyawan (Chiang and Birtsch, 2011). Pernyataan itu didukung oleh Davies (2001) yang menyatakan bahwa karyawan akan tetap bertahan lebih lama di dalam perusahaan, apabila mereka merasa bahwa pimpinan/manajer telah memberikan kompensasi yang layak atas kemampuan dan kontribusi mereka.

Intention to quit adalah sikap dari karyawan yang berkeinginan untuk keluar dari organisasi atau berpindah mengacu pada keinginan yang secara sadar dan disengaja untuk meninggalkan organisasi (Mohammad dkk., 2016). Keinginan untuk keluar atau intention to quit pada karyawan dapat mengakibatkan dampak 
buruk serta hal-hal yang tidak diinginkan oleh perusahaan. Intention to quit tersebut pada akhirnya akan mengarahkan karyawan pada turnover yang sebenarnya (Jauhar dkk., 2017).Nadiri dan Tanova (2010) juga menyatakan merupakan sebuah kemungkinan di masa depan bahwa karyawan memutuskan untuk keluar dari pekerjaannya saat ini, karena memiliki tingkat keinginan untuk keluar (intention to quit) yang tinggi.

Tingkat intention to quit yang tinggi akan mengarahkan karyawan pada turnover, yang sebenarnyadapat menjadi kerugian besar bagi setiap perusahaan dilihat dari biaya penggantian dan gangguan kerja yang akan terjadi (Cao et al., 2013; Rahman dan Zekeriya, 2013). Menurut pendapat Martin (2011) intention to quit adalah proses psikologis karyawan memikirkan pertimbangan untuk mencari pekerjaan alternatif yang lain, dan itu merupakan dampak dari ketidakpuasan terhadap pekerjaan yang dia miliki sekarang. Jadi, keinginan karyawan untuk keluar (intention to quit) dapat diawali dengan perilaku karyawan yang memiliki keinginan serta aktif untuk mencari pekerjaan baru akibat dari ketidakpuasan mereka berada di perusahaan saat ini.

Keinginan karyawan untuk keluar dari perusahaan dapat dikurangi apabila manajer sebagai pimpinan perusahaan lebih memperhatikan karyawannya dengan baik khususnya kepuasan kerja mereka (Robinson dan Aprilia, 2005). Tingkat kepuasan kerja karyawan yang rendah dapat ditunjukkan dengan sikap dan perilaku negatif terhadap pekerjaan serta tanggung jawab di lingkungan kerjanya (Agustina, 2008). Selanjutnya menurut penelitian Ucho et al. (2012) kepuasan kerja memiliki pengaruh signifikan negatif terhadap intention to quit. 
Abad ke-21 atau sering disebut abad millennial, terjadi peningkatanpopulasi manusia dan ditambah dengan intensitas persaingan perusahaan yang semakin tinggi, bagaimana cara perusahaan dikelola sangat berhubungan dengan gaya kepemimpinan transformasional yang merupakan faktor penting, sehingga mampu mengarahkan kinerja perusahaan menjadi lebih baik (Purit, 2016). Menurut Osabiya dan Ikenga (2015) kepemimpinan adalah aktivitas yang berdampak pada keadaan sosial di mana kualitas karakter pemimpin (leader) dapat mempengaruhi para pengikut atau bawahannya. Setiap pemimpin memiliki karakter dan gaya kepemimpinan mereka masing-masing yang dipengaruhi oleh budaya organisasi dan cenderung menghasilkan gaya manajemen yang merupakan standar perilaku bagi pemimpin tersebut (Shurbagi dan Zahari, 2012).

Gaya kepemimpinan transformasional adalah gaya kepemimpinan yang memiliki sifat karismatik serta memiliki peran strategis untuk mengarahkan karyawan, agar mampu membawa perusahaan mencapai tujuan yang telah ditentukan (Elizabeth dkk., 2016). Jika manajer atau pimpinan dapat menerapkan gaya kepemimpinan transformasional, maka akan meningkatkan kesetiaan karyawan dan rasa hormat kepada pimpinan serta bawahan akan merasa termotivasi untuk melakukan pekerjaan lebih dari yang diharapkan (Alam dkk., 2013). Pemimpin yang menggunakan gaya kepemimpinan transformasional sangat ahli dalam merubah seseorang dari yang awalnya hanya pengikut (follower) menjadi pemimpin (leader) dan dapat mempengaruhi mereka untuk bisa mengatasi kepentingan pribadi demi kebaikan organisasi (Greiman, 2009). Irawati dan Sudarsono (2010) mengatakan pada saat pemimpin telah menentukan 
tujuan yang ingin dicapai organisasi dan melibatkan karyawan secara langsung dapat meningkatkan motivasi kerja serta kepuasan kerja karyawan.

Tjoeiyanto (2010) menyatakan jika manajer dapat memenuhi seluruh hak karyawan, maka akan dapat meningkatkan kepuasan kerja karyawan di dalam perusahaan. Gul et al. (2012) juga menyatakan ada pengaruh negatif dan signifikan gaya kepemimpinan transformasional terhadap keinginan untuk keluar karyawan. Sedangkan, penelitian Long et al. (2012) dan Sartika (2014) menyatakan bahwa terdapat gaya kepemimpinan transformasional tidak berpengaruh terhadap keinginan untuk keluar karyawan.

Kepuasan kerja karyawan adalah ungkapan psikologis seorang karyawan terhadap pekerjaannya dengan persepsi dasar yang berkaitan dengan segala dimensi lingkungan pekerjaan yang ada di perusahaan, yaitu tugas sehari-hari yang dilakukan, rekan kerja, kondisi kerja serta kompensasi yang diterima (Gibson et al., 2008:30). Kreitner dan Kinicki (2005:60) berpendapat bahwa kepuasan kerja merupakan efektifitas dari respon emosional karyawan terhadap aspek pekerjaannya. Jadi, dapat disimpulkan bahwa kepuasan kerja merupakan suatu hal yang dapat membuat karyawan senang dalam pekerjaan ataupun keluar dari pekerjaan mereka, serta dapat memperlihatkan sikap individu karyawan terhadap pekerjaannya.

Kepuasan kerja juga adalah ungkapan rasa bahagia atau tidak bahagia dari karyawan saat menjalani pekerjaan di suatu perusahaan (Robbins, 2006:19). Selanjutnya Mas'ud (2004:19) menyatakan bahwa ada lima indikator yang dapat mempengaruhi kepuasan kerja karyawan yaitu pekerjaan karyawan itu sendiri, 
gaji atau kompensasi yang diterima, kesempatan untuk promosi jabatan, dukungan rekan kerja, supervisi atau pengawasan dari manajer dan pimpinan perusahaan. Karyawan yang memiliki kepuasan kerja rendah terhadap pekerjaan mereka akan cenderung lebih mudah memutuskan untuk keluar dan mencari tempat kerja lain dibandingkan karyawan yang telah merasa puas dan memiliki tingkat kepuasan kerja yang tinggi (Srinadi dan Supartha, 2015).

Pemimpin yang menerapkan gaya kepemimpinan transformasional lebih cenderung memberi perhatian kepada setiap individu, melibatkan karyawan atau bawahan pada pengambilan keputusan akan meningkatkan motivasi dan kepuasan kerja karyawan (Sari dan Sriathi, 2014). Fatima dkk. (2011) mengatakan bila gaya kepemimpinan transformasional memiliki pengaruh positif terhadap kepuasan kerja yang dapat menyebabkan keinginan untuk keluar menjadi lebih rendah. Yukl (2007:44) juga berpendapat bahwa pimpinan harus bisa menerapkan gaya kepemimpinan yang baik dan tepat, sehingga kepuasan kerja karyawan meningkat serta dapat mempengaruhi keinginan karyawan untuk keluar.Jadi bila pemimpin atau manajer perusahaan merupakan sumber rasa ketidaknyamanan untuk karyawan, maka keinginan karyawan untuk pergi dari perusahaan secara langsung akan meningkat (El-Badawy dan Bassiouny, 2014).

Penelitian ini akan dilakukan pada PT. Visionet Data Internasional Service Point Denpasaryang beralamat di Jalan Gunung Andakasa, Gang Dahlia No. 1, Denpasar. PT. Visionet Data Internasional adalah perusahaan pertama yang bergerak pada bidang IT (Information Technology) yang melayani jasa IT services di Indonesia. Layanan pengelolaan IT dari Visionet bertujuan agar klien dapat 
berfokus pada bisnis mereka tanpa mengkhawatirkan permasalahan IT bisnis yang mereka miliki. Berdasarkan wawancara dengan Service Area Coordinator (SAC) Visionet Service Point Denpasar, beberapa karyawan yang keluar dari perusahaan disebabkan oleh berbagai macam alasan. Salah satu alasan utamanya keinginan karyawan itu sendiri untuk keluar, karena melihat peluang karir yang lebih baik di perusahaan lain. Tabel 1 menunjukkan tingkat turnover karyawan PT Visionet Data Internasional Service Point Denpasar.

\section{Tabel 1.}

Data Turnover Karyawan PT. Visionet Data Internasional Service Point Denpasar Tahun 2015 - 2017

\begin{tabular}{|c|c|c|c|c|c|}
\hline Tahun & $\begin{array}{c}\text { Jumlah } \\
\text { Karyawan } \\
\text { Awal Tahun } \\
\text { (orang) } \\
\text { (1) }\end{array}$ & $\begin{array}{c}\text { Karyawan } \\
\text { Keluar } \\
\text { (orang) } \\
(2)\end{array}$ & $\begin{array}{c}\text { Karyawan } \\
\text { Masuk } \\
\text { (orang) } \\
\text { (3) }\end{array}$ & $\begin{array}{c}\text { Jumlah } \\
\text { Karyawan } \\
\text { Akhir Tahun } \\
\text { (orang) } \\
(4)\end{array}$ & $\begin{array}{c}\text { Turnover } \\
\text { Karyawan } \\
(\%) \\
(5)=\frac{(2)}{(1)+(4)}\end{array}$ \\
\hline 2015 & 48 & 10 & 7 & 45 & 10,75 \\
\hline 2016 & 45 & 12 & 10 & 43 & 13,63 \\
\hline 2017 & 43 & 13 & 18 & 48 & 14,28 \\
\hline
\end{tabular}

Sumber: PT. Visionet Data Internasional Service Point Denpasar, 2018

Berdasarkan tabel diatas terlihat bahwa tingkat turnover di perusahaan ini selama 3 tahun selalu berada pada angka diatas $10 \%$ dan terus meningkat.Penelitian Ridlo (2012:5) menyatakan tingkat turnover karyawan diatas angka $10 \%$ dalam setahun tergolong tinggi dan dapat menyebabkan kerugian bagi perusahaan. Tingkat turnover yang tinggi biasanya menandakanbahwa karyawan memiliki intention to quit yang tinggi pula, karena intention to quit tersebut nantinya akan mengarahkan karyawan pada turnover (Jauhar dkk., 2017).

Social exchange theory atau teori pertukaran sosial telah digunakan para peneliti organisasi sebagai kerangka yang memiliki pengaruh untuk menjelaskan perilaku kerja seseorang (Mitchell dkk., 2005). Penelitian Mitchell dkk. (2005) 
menyatakan ketika seseorang memberikan orang lain sumber daya yang berharga dan bermanfaat, maka akan muncul kewajiban untuk mengembalikan sumber daya tersebut. Serangkaian kegiatan tukar-menukar tersebut dapat memperkuat hubungan antara pihak-pihak yang terlibat dalam pertukaran, yang pada akhirnya menghasilkan perilaku yang bermanfaat dan produktif (Blau, 1964).

Pamudji (2009:151) berpendapat bahwa teori ini adalah pandangan bahwa interaksi sosial digambarkan melalui tukar-menukar yang terjadi di antara anggota kelompok yang dengan pengorbanan mereka masing-masing dapat memberikan kontribusi dan dengan pengorbanan dari anggota atau kelompok lain dapat menerima imbalan. Interaksi akan berlangsung secara terus menerus, dan dilakukan oleh seluruh anggota yang ada di organisasi, karena merasa kegiatan tukar-menukar secara sosial ini mampu saling memberikan keuntungan. Dengan begitu pemimpin (leader) dan yang dipimpin (follower), serta anggota lainnya mampu melakukan tukar-menukar sosial yang saling menguntungkan dengan saling memberi dan menerima (Pamudji, 2009:151).

Seorang pemimpin harus mampu menggerakan seluruh anggota organisasi. Gerakan tersebut dapat terjadi apabila terdapat hubungan yang saling menguntungkan di dalam suatu organisasi. Jadi dapat disimpulkan bahwa yang ditekankan dari teori ini adalah adanya memberi (give) dan menerima (take) diantara pemimpin dan anggota dari organisasi yang dipimpinnya, karena itu teori ini juga sering dikatakan sebagai teori saling memberi dan menerima (Pamudji, 2009:151). 
Intention to quit adalah keinginan karyawan untuk keluar dari pekerjaannya di suatu perusahaan, tapi belum diwujudkan dengan tindakan nyata (Bockermanand Ilmakunnas, 2007). Penelitian Nadiri dan Tanova (2010) menyatakan terdapat kemungkinan di masa depan dimana karyawan memutuskan untuk keluar dari pekerjaannya saat ini, karena memiliki tingkat keinginan untuk keluar (intention to quit) yang tinggi. Penelitian Jauhar dkk. (2017) juga menyatakan bahwa intention to quit pada akhirnya akan mengarahkan karyawan pada turnover yang sebenarnya. Tingkat keinginan untuk keluar yang terlalu tinggi memiliki potensi yang akan membahayakan kinerja perusahaan, apabila karyawan yang berbakat sering dan banyak meninggalkan perusahaan (Jauhar dkk., 2017).

Masalah selanjutnya adalah karyawan yang tetap diam dan berada di dalam perusahaan, akan mengalami penurunan tingkat kepuasan kerja yang disebabkan karena rekan kerja mereka telah meninggalkan perusahaan (Kanwar dkk., 2012). Munculnya keinginan karyawan untuk keluar disebabkan karena adanya masalah kepuasan kerja, tekanan dari pimpinan, persaingan antar sesama karyawan dan masalah eksternal lain misalnya terdapat tawaran kerja yang lebih baik di perusahaan lain (Prihartono, 2013). Menurut penelitian Tzeng (2002) faktor utama yang paling mempengaruhi intention to quit pada karyawan adalah ketidakpuasan kerja. Penelitian dari Firth et al. (2004) juga menyatakan keinginan karyawan untuk keluar dari perusahaan sebagian besar dipengaruhi oleh ketidakpuasan kerja. 
Dimaculangan dan Aguiling (2012) meneliti dampak langsung dan tidak langsung dari gaya kepemimpinan transformasional terhadap keinginan untuk keluar seorang salesman melalui iklim etis, person-organization fit dan komitmen organisasi. Penelitian tersebut menyatakan bahwa gaya kepemimpinan transformasional berkontribusi dalam mengelola keinginan keluar karyawan melalui peningkatan kinerja finansial perusahaan. Menurut penelitian Dewi dan Subudi (2015) gaya kepemimpinan transformasional memiliki pengaruh negatif signifikan terhadap intention to quit. Penelitian dari El-Badawy dan Bassiouny (2014) juga menyatakan bahwa gaya kepemimpinan transformasional memiliki pengaruh terhadap keinginan karyawan untuk keluar dari perusahaan.

Banyak perubahan lingkungan bisnis yang terjadi di jaman modern ini, kepemimpinan di dalam organisasi maupun perusahaan juga ikut mengalami beberapa perubahan dengan munculnya gaya kepemimpinan transformasional. Gaya kepemimpinan transformasional adalah gaya kepemimpinan yang memiliki sifat karismatik serta memiliki peran strategis untuk mengarahkan karyawan, agar mampu membawa perusahaan mencapai tujuan yang telah ditentukan (Elizabeth dkk., 2016). Pemimpin yang menggunakan gaya kepemimpinan transformasional mempunyai kemampuan untuk mendorong dan memotivasi pengikut atau karyawannya untuk mencapai hasil yang maksimal serta melampaui harapan perusahaan (Alam dkk., 2013). Penelitian Farahani dkk. (2011), menyatakan bahwa untuk dapat menjaga stabilitas organisasi dan mempertahankan karyawan dengan komitmen organisasional yang tinggi, memilih pemimpin yang menggunakan gaya kepemimpinan transformasional dengan penekanan terhadap 
individu yang memiliki kecerdasan emosional tinggi dapat membantu tercapainya tujuan perusahaan.

Gul et al. (2012), Farahani dkk. (2011) dan Jauhar dkk. (2017) menyatakan terdapat pengaruh negatif dan signifikan gaya kepemimpinan transformasional terhadap keinginan untuk keluar karyawan. Berdasarkan pendapat Emery dan Barker (2007) gaya kepemimpinan transformasional juga akan lebih meningkatkan kepuasan kerja karyawan dengan membagikan kemampuannya untuk bisa menyampaikan visi dan misi serta memberikan stimulasi intelektual, disamping itu gaya kepemimpinan transformasional dapat mendorong pengikutnya untuk menjalankan banyak tanggung jawab (otonomi), tugas kerja seperti itu dapat meningkatkan keberhasilan organisasi. Tjoeiyanto (2010) menyatakan jika manajer dapat memenuhi seluruh hak karyawan, maka akan dapat meningkatkan kepuasan kerja karyawan di dalam perusahaan.

Hasil penelitian Dewi dan Subudi (2015) juga menyatakan bahwa gaya kepemimpinan transformasional memiliki pengaruh positif signifikan terhadap kepuasan kerja. Dapat dikatakan apabila pemimpin atau manajer perusahaan dapat membangkitkan antusiasme karyawan untuk bekerja, maka kepuasan kerja karyawan pada saat bekerja akan semakin meningkat (Purnomo dan Cholil, 2010). Munir et al. (2012) berpendapat bahwa gaya kepemimpinan transformasional dan kepuasan kerja adalah dua elemen penting untuk menciptakan perusahaan yang sehat dan produktif.

Robinson dan Aprilia (2005) menyatakan keinginan karyawan untuk keluar (intention to quit) dari perusahaan dapat dikurangi apabila manajer atau 
pimpinan perusahaan lebih memperhatikan karyawannya dengan baik khususnya pada kepuasan kerja mereka. Srinadi dan Supartha (2015) berpendapat bahwa karyawan yang memiliki kepuasan kerja rendah terhadap pekerjaan mereka, akan cenderung lebih mudah memutuskan untuk keluar dan mencari tempat kerja lain dibandingkan karyawan yang telah memiliki tingkat kepuasan kerja yang tinggi. PT. Visionet Data Internasional Service Point Denpasar akan mengalami kerugian jika nanti terdapat karyawan yang keluar dari pekerjaannya secara mendadak, karena perusahaan tersebut harus segera mencari karyawan baru yang akan memerlukan banyak biaya tambahan baik dari segi biaya finansial maupun waktu.

Kepuasan kerja adalah ungkapan rasa bahagia atau tidak bahagia dari karyawan saat menjalani pekerjaan di suatu perusahaan (Robbins, 2006:19). Kepuasan kerja adalah suatu hal yang bersifat individu dan pasti setiap individu memiliki tingkat kepuasan kerja yang berbeda dengan nilai-nilai yang berlaku pada dirinya, jika seluruh aspek dalam pekerjaan telah sesuai dengan keinginannya maka semakin tinggi kepuasan kerja yang akan dirasakan, karyawan yang telah puas dengan pekerjaannya akan lebih inovatif dan kreatif untuk bekerja agar perusahaan dapat terus tumbuh dan berkembang serta dapat membawa perubahan positif untuk perusahaan (Fatima dkk. 2011). Penelitian lain yang telah dilakukan oleh Gibson et al. (2008:30) menunjukkan bahwa kepuasan kerja adalah ekspresi individu yang telah mencapai kesejahteraan pribadi dari melakukan pekerjaan yang diminta.

Dewi dan Subudi (2015) menyatakan bahwa gaya kepemimpinan transformasional memiliki pengaruh negatif signifikan terhadap intention to quit. 
Gul et al. (2012), Farahani dkk. (2011) dan Jauhar dkk. (2017) menyatakan terdapat pengaruh negatif yang signifikan diantara gaya kepemimpinan transformasional terhadap keinginan untuk keluar karyawan. Penelitian-penelitian tersebut menyatakan bahwa gaya kepemimpinan transformasional berkontribusi dalam mengelola keinginan keluar karyawan pada suatu perusahaan.

$\mathrm{H}_{1}$ : Gaya kepemimpinan transformasional berpengaruh negatif dan signifikan terhadap intention to quit.

Berdasarkan pendapat Emery dan Barker (2007) gaya kepemimpinan transformasional akan lebih meningkatkan kepuasan kerja karyawan dengan membagikan kemampuannya untuk bisa menyampaikan visi dan misi serta memberikan stimulasi intelektual, disamping itu gaya kepemimpinan transformasional dapat mendorong pengikutnya untuk menjalankan banyak tanggung jawab (otonomi), tugas kerja seperti itu dapat meningkatkan keberhasilan organisasi. Tjoeiyanto (2010) menyatakan jika manajer dapat memenuhi seluruh hak karyawan, maka akan dapat meningkatkan kepuasan kerja karyawan di dalam perusahaan. Hasil penelitian Dewi dan Subudi (2015) juga menyatakan bahwa gaya kepemimpinan transformasional memiliki pengaruh positif signifikan terhadap kepuasan kerja.

Penelitian tersebut didukung oleh Cumming et al. (2010) yang mengatakan bahwa gaya kepemimpinan yang hanya fokus terhadap output yang dihasilkan karyawan, tidak peduli dengan kepuasan kerja dan tidak memikirkan perasaan karyawan nantinya akan gagal mencapai kinerja terbaik karyawan. Kepuasan kerja merupakan salah satu faktor terpenting dalam fungsi organisasi 
dan cenderung dipengaruhi oleh budaya dan kepemimpinan perusahaan (Girma, 2016).

$\mathrm{H}_{2}$ : Gaya kepemimpinan transformasional berpengaruh positif dan signifikan terhadap kepuasan kerja.

Penelitian dari Berry (2010) menyatakan bahwa kepuasan kerja mampu membawa dampak yang signifikan terhadap keinginan untuk keluar. Penelitian Srinadi dan Supartha (2015) menyatakan bahwa kepuasan kerja berpengaruh negatif terhadap intention to quit. Pernyataan tersebut didukung oleh penelitian Tzeng (2002) yang berpendapat bahwa faktor utama yang paling mempengaruhi intention to quit pada karyawan adalah ketidakpuasan kerja.

Keinginan untuk keluar (intention to quit) dari suatu perusahaan akan diawali dengan munculnya keinginan kuat karyawan yang dipicu akibat ketidakpuasan karyawan terhadap pekerjaannya (Jimad, 2011). Penelitian Firth et al. (2004) juga menyatakan keinginan karyawan untuk keluar dari perusahaan sebagian besar dipengaruhi oleh kepuasan kerja.

$\mathrm{H}_{3}$ : Kepuasan kerja berpengaruh negatif dan signifikan terhadap intention to quit

Fatima dkk. (2011) menyatakan gaya kepemimpinan transformasional memiliki pengaruh positif dengan kepuasan kerja yang selanjutnya dapat menurunkan tingkat keinginan untuk keluar menjadi karyawan. Keinginan karyawan untuk keluar dari perusahaan muncul akibat adanya masalah kepuasan kerja, tekanan dari pimpinan, persaingan antar sesama karyawan dan masalah eksternal lain misalnya terdapat tawaran kerja yang lebih baik di perusahaan lain (Prihartono, 2013). 
Yukl (2007:44) berpendapat bahwa pimpinan harus bisa menerapkan gaya kepemimpinan yang tepat dan baik, sehingga kepuasan kerja karyawan meningkat serta nantinya dapat mempengaruhi keinginan karyawan untuk keluar.Robinson dan Aprilia (2005) juga menyatakan keinginan karyawan untuk keluar (intention to quit) dari perusahaan dapat dikurangi apabila manajer atau pimpinan perusahaan lebih memperhatikan karyawannya dengan baik khususnya pada kepuasan kerja mereka. Jadi bila pemimpin atau manajer perusahaan merupakan sumber rasa ketidaknyamanan untuk karyawan, maka keinginan karyawan untuk pergi dari perusahaan secara langsung akan meningkat (El-Badawy dan Bassiouny, 2014).

$\mathrm{H}_{4}$ : Peran mediasi kepuasan kerja dalam pengaruh negatif dan signifikan gaya kepemimpinan transformasional terhadap intention to quit.

\section{METODE PENELITIAN}

Penelitian ini akan dilakukan di PT. Visionet Data Internasional Service Point Denpasar yang beralamat di Jalan Gunung Andakasa, Gang Dahlia No. 1, Denpasar. Pertimbangan dipilihnya perusahaan ini sebagai lokasi penelitian, karena berdasarkan penelitian awal terlihat adanya permasalahan intention to quit. Hal ini terindikasi dari tingginya tingkat turnover karyawan PT Visionet Data Internasional Service Point Denpasar.

Dalam penelitian ini yang menjadi populasi adalah seluruh karyawan PT. Visionet Data Internasional Service Point Denpasar per Juli 2018 yaitu sebanyak 48 orang karena tidak termasuk 1 (satu) orang pimpinan perusahaan, sebab penelitian ini ingin meneliti variabel gaya kepemimpinan transformasional. 
Sampel dalam penelitian ini yaitu: 48 orang, karena teknik sampel yang akan digunakan adalah sampling jenuh. Pada penelitian ini terdapat sampel sebanyak 48 responden yang dapat dilihat pada Tabel 2.

Tabel 2.

Populasi dan Sampel

\begin{tabular}{ccc}
\hline No & Jabatan & Jumlah Karyawan (orang) \\
\hline 1 & Service Area Technical Support (SATS) & 1 \\
2 & Service Point Leader (SPL) & 1 \\
3 & Technical Associate Service (TAS) & 3 \\
4 & Admin Logistik & 4 \\
5 & Staf Admin & 2 \\
6 & Teknisi & 37 \\
& Jumlah & 48 \\
\hline
\end{tabular}

Sumber: PT. Visionet Data Internasional Service Point Denpasar, 2018

Analisis jalur adalah analisis regresi linier berganda yang digunakan untuk memprediksi hubungan kausalitas diantara variabel bebas yang mempengaruhi variabel terikat, melalui satu atau lebih variabel perantara yang berfungsi ganda (mediasi) secara langsung maupun tidak langsung (Utama, 2016:159). Ridwan dan Kuncoro (2012:121) menyatakan bahwa analisis jalur (path analysis) bertujuan menganalisis pola hubungan diantara variabel untuk mengetahui dan memahami pengaruh langsung maupun tidak langsung variabel bebas terhadap variabel terikat.

\section{HASIL PENELITIAN DAN PEMBAHASAN}

Penyebaran kuesioner dilakukan di PT. Visionet Data Internasional Service Point Denpasar dengan responden yang berjumlah 48 orang dan kuesioner yang kembali sebanyak 40 lembar. Jadi tingkat responden yang mengembalikan kuesioner adalah sebesar $83 \%$, sebab 8 orang responden tidak mengembalikan kuesioner sesuai dengan batas waktu yang telah ditentukan. Respoden dalam 
penelitian ini hanya berjumlah 40 orang, dengan profil responden dalam Tabel 3 sebagai berikut:

Tabel 3.

Profil Responden Penelitian

\begin{tabular}{cccc}
\hline Kriteria & Sub kriteria & $\begin{array}{c}\text { Jumlah } \\
(\text { orang) }\end{array}$ & $\begin{array}{c}\text { Persentase } \\
(\boldsymbol{\%})\end{array}$ \\
\hline Jenis kelamin & Laki-laki & 38 & 95 \\
& Perempuan & 2 & 5 \\
Umur & $25-30$ tahun & 10 & 25 \\
& $31-35$ tahun & 30 & 75 \\
Pendidikan terakhir & SMA/SMK & 32 & 80 \\
& Diploma (D3) & 5 & 12,5 \\
Lama bekerja & Sarjama (S1) & 3 & 7,5 \\
& $<1$ tahun & 2 & 5 \\
& 1 tahun - 2 tahun & 21 & 52,5 \\
& $>3$ tahun & 17 & 42,5 \\
\hline
\end{tabular}

Sumber: Data diolah, 2018

Tabel 3 memperlihatkan profil responden dimana karyawan laki-laki lebih dominan dibandingkan karyawan perempuan yaitu sebanyak 38 orang, karena banyak karyawan bertugas sebagai teknisi. Usia sebagian besar karyawan adalah 31 - 35 tahun. Banyak karyawan PT. Visionet Data Internasional Service Point Denpasar mempunyai pendidikan terakhir SMA/SMK, selanjutnya karyawan yang lama bekerjanya 1 - 2 tahun lebih banyak bila dibandingkan dengan yang bekerja dibawah 1 tahun maupun diatas 3 tahun.

Perhitungan koefisien path dilakukan dengan analisis regresi melalui software SPSS version 22 for windows diperoleh hasil sebagai berikut:

Tabel 4.

Hasil Analisis Jalur Persamaan Regresi 1

\begin{tabular}{|c|c|c|c|c|c|}
\hline \multirow[t]{2}{*}{ Model } & \multicolumn{2}{|c|}{$\begin{array}{c}\text { Unstandardized } \\
\text { Coefficients }\end{array}$} & \multicolumn{2}{|c|}{ Standardized Coefficient } & \multirow[b]{2}{*}{ Sig. } \\
\hline & B & Std.Error & Beta & $\mathbf{T}$ & \\
\hline (Constant) & 10,498 & 2,640 & & 3,997 & 0,000 \\
\hline $\begin{array}{l}\text { Gaya kepemimpinan } \\
\text { transformasional (X1) }\end{array}$ & 0,681 & 0,149 & 0,596 & 4,572 & 0,000 \\
\hline$: 0,355$ & & & & & \\
\hline F Hitung : 20,899 & & & & & \\
\hline Sig. F : 0,000 & & & & & \\
\hline
\end{tabular}


Berdasarkan hasil analisis jalur persamaan regresi 1 seperti yang disajikan pada Tabel 3, maka persamaan regresinya adalah sebagai berikut:

$$
\begin{aligned}
& \mathrm{Y}_{1}=\rho_{1} \mathrm{X}+\mathrm{e}_{1} \ldots \ldots \\
& \mathrm{Y}_{1}=0,681 \mathrm{X}+\mathrm{e}_{1}
\end{aligned}
$$

\section{Tabel 5.}

Hasil Analisis Jalur Persamaan Regresi 2

\begin{tabular}{cccccc}
\hline Model & \multicolumn{2}{c}{$\begin{array}{c}\text { Unstandardized } \\
\text { Coefficients }\end{array}$} & \multicolumn{2}{c}{ Standardized Coefficients } & \\
& B & Std.Error & Beta & T & Sig. \\
\hline (Constant) & 16,027 & 3,888 & & 4,122 & 0,000 \\
Gaya kepemimpinan & 0,124 & 0,201 & 0,111 & 0,619 & 0,540 \\
transformasional (X1) & $-0,701$ & 0,230 & $-0,546$ & -3.054 & 0,004 \\
Kepuasan kerja (Y1) & & & & & \\
$\mathrm{R}^{2} \quad: 0,238$ & & & & & \\
$\mathrm{~F} \mathrm{Hitung} \mathrm{:} \mathrm{5,777}$ & & & & & \\
Sig. F :0,007 & & & &
\end{tabular}

Pada Tabel 5 terlihat hasil analisis jalur persamaan regresi 2 diatas, maka persamaan regresinya adalah sebagai berikut:

$$
\begin{aligned}
& Y_{2}=\rho_{2} X+\rho_{3} Y_{1}+e_{2} \ldots \ldots \ldots \\
& Y_{2}=0,124 X+\left(-0,701 Y_{1}\right)+e_{2}
\end{aligned}
$$

Berdasarkan model persamaan regresi 1 dan regresi 2, maka dapat disusun model diagram jalur akhir, tapi sebelum menyusun model diagram jalur akhir, terlebih dahulu dihitung nilai standar error sebagai berikut:

$$
\begin{aligned}
& \mathrm{Pe}_{1}=\sqrt{1-} \mathrm{R}_{1}{ }^{2} \ldots \ldots \ldots \ldots \ldots \ldots \ldots \ldots \\
& \mathrm{Pe}_{1}=\sqrt{1-} \mathrm{R}_{1}{ }^{2}=\sqrt{1-} 0,355=0,645 \\
& \mathrm{Pe}_{2}=\sqrt{1-} \mathrm{R}_{2}{ }^{2}=\sqrt{1-} 0,238=0,762
\end{aligned}
$$

Berdasarkan perhitungan pengaruh error $\left(\mathrm{Pe}_{1}\right)$, didapatkan hasil pengaruh error $\left(\mathrm{Pe}_{1}\right)$ sebesar 0,645 dan pengaruh error $\left(\mathrm{Pe}_{2}\right)$ sebesar 0,762. Hasil koefisien determinasi total adalah sebagai berikut:

$$
\mathrm{R}_{\mathrm{m}}^{2}=1-\left(\mathrm{Pe}_{1}\right)^{2}\left(\mathrm{Pe}_{2}\right)^{2}
$$




$$
\begin{aligned}
=1 & -(0,645)^{2}(0,762)^{2} \\
& =1-(0,419)(0,580) \\
& =1-0,243 \\
& =0,756
\end{aligned}
$$

Nilai determinasi total sebesar 0,756 mempunyai arti bahwa sebesar 75,6\% variabel intention to quit dipengaruhi oleh variabel gaya kepemimpinan transformasional dan kepuasan kerja, sedangkan sisanya sebesar 24,4 \% dipengaruhi oleh faktor lain yang tidak dimasukkan ke dalam model penelitian ini.

Pada hasil analisis nilai masing-masing $\mathrm{p}_{1}$ adalah $0,124, \mathrm{p}_{2}$ adalah 0,681 dan $\mathrm{p}_{3}$ adalah $-0,701$. Nilai $\mathrm{p}_{\text {vvalue }}$ melihat sebuah model menghasilkan bentuk hubungan yang valid dengan p_value (sig.t) $<0,05$. Nilai p_value masng-masing adalah $\mathrm{p}_{1}$ sebesar $0,540>0,05, \mathrm{p}_{2}$ sebesar $0,000<0,05$ sedangkan $\mathrm{p}_{3}$ sebesar $0,004<0,05$. Dengan demikian jalur $\mathrm{p}_{2}$ dan $\mathrm{p}_{3}$ yang ada pada model ini dapat dinyatakan signifikan sedangkan $\mathrm{p}_{1}$ tidak signifikan.

Tabel 6.

Pengaruh Langsung, Pengaruh Tidak Langsung dan Pengaruh Total Variabel Gaya Kepemimpinan Transformasional $\left(\mathbf{X}_{1}\right)$, Kepuasan Kerja $\left(\mathbf{Y}_{1}\right)$ dan Intention to quit $\left(\mathrm{Y}_{2}\right)$

\begin{tabular}{cccc}
\hline Pengaruh Variabel & Pengaruh Langsung & $\begin{array}{c}\text { Pengaruh tidak langsung } \\
\left(\mathbf{p}_{\mathbf{1}} \mathbf{x} \mathbf{p}_{\mathbf{3}}\right)\end{array}$ & Pengaruh total \\
\hline $\mathrm{X}_{1} \longrightarrow \mathrm{Y}_{2}$ & 0,124 & $-0,59$ & $-0,466$ \\
$\mathrm{X}_{1} \longrightarrow \mathrm{Y}_{1}$ & 0,681 & - & 0,681 \\
$\mathrm{Y}_{1} \longrightarrow$ & - & - & $-0,714$ \\
\hline Sumber: Data diolah, 2018 & $-0,714$ & &
\end{tabular}

Pengaruh gaya kepemimpinan transformasional terhadap intention to quit dimediasi oleh kepuasan kerja dapat diperoleh dengan menggunakan rumus:

$$
\begin{aligned}
\mathrm{X}_{1} \longrightarrow \mathrm{Y}_{1} \longrightarrow \mathrm{Y}_{2} & =\left(\mathrm{p}_{1} \mathrm{x} \mathrm{p}_{3}\right) \\
& =(0,124 \mathrm{x}-0,714)
\end{aligned}
$$




$$
=-0,59
$$

Nilai sebesar -0,59 mempunyai arti bahwa pengaruh tidak langsung gaya kepemimpinan transformasional terhadap intention to quit yang dimediasi oleh kepuasan kerja yaitu $59 \%$.

Pengaruh total diperoleh dan hasil perhitungan rumus:

Total Effect $=$ pengaruh langsung + pengaruh tidak langsung

$$
\begin{aligned}
= & \mathrm{p} 2+(\mathrm{p} 1 \times \mathrm{p} 3) \\
= & 0,681+(0,124 \times-0,714) \\
= & 0,592
\end{aligned}
$$

Pengaruh total gaya kepemimpinan transformasional, kepuasan kerja dan intention to quit di PT. Visionet Data Internasional Service Point Denpasar adalah 0,592 atau $59,2 \%$.

Hasil analisis menunjukkan bahwa gaya kepemimpinan transformasional tidak berpengaruh negatif dan signifikan terhadap intention to quit. Hasil tersebut terlihat pada Tabel 4 yang memperlihatkan bahwa nilai signifikansi untuk pengaruh variabel gaya kepemimpinan transformasional adalah 0,540 terhadap variabel intention to quit. Ini menandakan bahwa walaupun manajer menggunakan gaya kepemimpinan transformasional dalam memimpin, maka keinginan karyawan untuk keluar belum tentu akan berkurang. Karyawan PT. Visionet Data Internasional Service Point Denpasar memperlihatkan bahwa gaya kepemimpinan transformasional yang rendah tidak selalu menyebabkan tingginya intention to quit, begitu juga sebaliknya gaya kepemimpinan transformasional yang tinggi tidak secara langsung menyebabkan rendahnya intention to quit. 
Hasil penelitian ini didukung oleh penelitian Long et al. (2012), Peachey et al. (2014), dan Sartika (2014) yang menyatakan bahwa gaya kepemimpinan transformasional tidak berpengaruh negatif dan signifikan terhadap keinginan karyawan untuk keluar (intention to quit). Sedangkan, hasil ini berlawan dengan penelitian Gul et al. (2012), Farahani dkk. (2011), Dewi dan Subudi (2015), serta Jauhar dkk. (2017) yang menyatakan terdapat pengaruh negatif yang signifikan gaya kepemimpinan transformasional terhadap keinginan karyawan untuk keluar

BerdasarkanTabel 4 terlihat bahwa nilai signifikansi untuk pengaruh variabel gaya kepemimpinan transformasional sebesar 0,000 terhadap variabel kepuasan kerja. Hasil tersebut membuktikan bahwa variabel gaya kepemimpinan transformasional berpengaruh positif dan signifikan terhadap kepuasan kerja, dimana pemimpin yang menerapkan gaya kepemimpinan transformasional lebih cenderung memberi perhatian kepada setiap individu dan melibatkan karyawan pada pengambilan keputusan yang akan meningkatkan kepuasan kerja karyawan (Sari dan Sriathi, 2014). Hasil penelitian ini didukung oleh Cumming et al. (2010), Dewi dan Subudi (2015), Emery dan Barker (2007), Girma (2016), dan Tjoeiyanto (2010) yang mengatakan bahwa gaya kepemimpinan transformasional memiliki pengaruh positif signifikan terhadap kepuasan kerja.

Hasil analisis hipotesis menunjukkan bahwa kepuasan kerja berpengaruh negatif dan signifikan terhadap intention to quit, karena pada Tabel 5 menunjukkan nilai signifikansi pengaruh variabel kepuasan terhadap intention to quit sebesar 0,004 < 0,05. Jadi bila karyawan telah memiliki kepuasan kerja yang tinggi, keinginannya untuk meninggalkan perusahaan akan berkurang.Hasil 
penelitian ini cukup mendukung hasil penemuan penelitian sebelumnya dari Berry (2010),Jimad (2011), Srinadi dan Supartha (2015), Firth et al. (2004) dan Tzeng (2002) yang menyatakan kepuasan kerja berpengaruh negatif dan signifikan terhadap tingkat intention to quit karyawan.

Hasil analisis hipotesis memperoleh hasil bahwa nilai koefisien pengaruh tidak langsung untuk hipotesis ini sebesar -0,59 atau 59\%. Hasil tersebut menunjukkan bahwa kepuasan kerja memiliki peran mediasi dalam pengaruh negatif dan signifikan gaya kepemimpinan transformasional terhadap intention to quit. Jadi jika tingkat gaya kepemimpinan transformasional tinggi, maka semakin tinggi pula kepuasan kerja karyawan PT. Visionet Data Internasional Service Point Denpasar dan keinginan karyawan untuk keluar dari perusahaan pun menjadi semakin rendah.

Keinginan karyawan untuk keluar (intention to quit) dari perusahaan dapat dikurangi apabila manajer atau pimpinan perusahaan lebih memperhatikan karyawannya dengan baik khususnya pada kepuasan kerja mereka (Robinson dan Aprilia, 2005). Hasil penelitian ini didukung oleh Fatima dkk. (2011), Prihartono (2013), Yukl (2007) yang menyatakan gaya kepemimpinan transformasional memiliki pengaruh positif terhadap kepuasan kerja yang nantinya akan dapat menyebabkan keinginan untuk keluar karyawan menjadi lebih rendah.

Implikasi hasil penelitian bertujuan untuk menekankan pada manfaat nyata dari hasil penelitian untuk mempertahankan karyawan dengan mengurangi intention to quit pada karyawan PT Visionet Data Internasional Service Point Denpasar, dengan meningkatkan gaya kepemimpinan transformasional dan 
kepuasan kerja. Adapun terdapat beberapa implikasi hasil penelitian ini, sebagai berikut:

Pertama, responden sangat setuju bahwa gaya kepemimpinan transformasional mampu meningkatkan kepuasan kerja. Indikator dari gaya kepemimpinan transformasional, yaitu: motivasi inspiratif sangat diperlukan untuk meningkatkan kepuasan kerja. Bila manajer menggunakan gaya kepemimpinan transformasional, maka manajer tersebut akan mampu memberi motivasi yang inspiratif kepada karyawan, kemudian secara langsung akan berpengaruh terhadap kepuasan kerja karyawan di perusahaan. Jadi penting bagi pimpinan perusahaan untuk selalu menggunakan gaya kepemimpinan transformasional.

Kedua, peningkatan kepuasan kerja dalam perusahaan akan dapat menurunkan keinginan karyawan untuk keluar. Pernyataan responden tentang saya memiliki suatu pekerjaan yang dapat memberikan tugas yang menarik untuk kemajuan diri saya memiliki rata-rata tertinggi. Hal ini menunjukkan bahwa setiap karyawan di PT Visionet Data Internasional Service Point Denpasar memiliki pekerjaan menarik yang berguna untuk kemajuan diri karyawan itu sendiri. Menurut responden hal tersebut akan mampu meningkatkan kepuasan kerja yang secara langsung mengurangi intention to quit karyawan.

\section{SIMPULAN DAN SARAN}

Menurut hasil penelitian yang telah dilakukan pada PT Visionet Data Internasional Service Point Denpasar dapat diberikan simpulan yaitu gaya kepemimpinan transformasional tidak berpengaruh signifikan terhadap intention 
to quit. Hasil ini cukup menarik karena walaupun manajer menggunakan gaya kepemimpinan transformasional yang memiliki sifat karismatik, belum tentu akan mampu mengurangi tingkat intention to quit karyawan di perusahaan.

Gaya kepemimpinan transformasional berpengaruh positif dan signifikan terhadap kepuasan kerja. Hal ini berarti manajer dengan gaya kepemimpinan transformasional mampu lebih meningkatkan kepuasan kerja karyawan.

Kepuasan kerja berpengaruh negatif dan signifikan terhadap intention to quit. Jadi kepuasan kerja yang rendah akan menyebabkan tingginya intention to quit, begitu juga sebaliknya kepuasan kerja yang tinggi secara langsung dapat menyebabkan rendahnya intention to quit karyawan.

Peran mediasi kepuasan dalam pengaruh negatif dan signifkan gaya kepemimpinan transformasional terhadap intention to quit. Jadi semakin tinggi gaya kepemimpinan transformasional, maka semakin tinggi juga kepuasan kerja dan keinginan karyawan untuk keluar dari perusahaan pun menjadi semakin rendah. Berdasarkan Utama (2016:167) kepuasan kerja memiliki peran mediasi penuh, karena variabel gaya kepemimpinan transformasional tidak berpengaruh signifikan terhadap intention to quit. Namun, gaya kepemimpinan transformasional berpengaruh signifikan terhadap kepuasan kerja. Kemudian variabel kepuasan kerja berpengaruh signifikan terhadap intention to quit.

Hasil penelitian ini jika dikaitan dengan Social Exchange Theory, maka dapat disimpulkan pimpinan harus bisa menerapkan gaya kepemimpinan yang tepat dan baik, agar kepuasan kerja karyawan meningkat serta nantinya dapat mempengaruhi keinginan karyawan untuk keluar dari perusahaan. Dengan begitu 
akan ada kegiatan memberi dan menerima yang menguntungkan diantara pemimpin dan anggotanya. Hasil penelitian ini juga memperlihatkan bahwa variabel yang paling berpengaruh terhadap intention to quit adalah kepuasan kerja. Saran yang dapat diberikan berdasarkan hasil penelitian pada PT. Visionet Data Internasional Service Point Denpasar adalah untuk manajer dan pimpinan perusahaan disarankan untuk memberi perhatian kepada karyawan secara individual.

Perusahaan dapat melakukan upaya untuk mengurangi tingginya tingkat intention to quit, dengan cara memberikan kesempatan promosi kepada karyawan yang sudah berkontribusi besar terhadap perusahaan.

Untuk penelitian selanjutnya disarankan supaya memperluas wilayah atau lokasi penelitian, melihat peneliti hanya melakukan penelitian pada satu Service Point yaitu Service Point Denpasar, Bali. Penelitian selanjutnya juga disarankan menambah variabel lain yang dapat mempengaruhi intention to quit, misalnya budaya organisasi, motivasi, semangat kerja dan komitmen organisasional.

\section{REFERENSI}

Agustina, L. (2008). Pengaruh Work Family Conflict Terhadap Job Satisfaction Dan Turnover Intention Pada Profesi Akuntan Publik (Studi Empiris Pada Kantor Akuntan Publik di DKI Jakarta dan Bandung). Jurnal Ilmiah Akuntansi, 7 (2), hal.126-138.

Alam, T. M., T. Alsabji, dan K. Raharjo. (2013). Pengaruh Kepemimpinan Transformasional dan Budaya Organisasi Terhadap Kepuasan Kerja Pegawai (Studi Pada Pegawai Kantor Pusat PT Pelabuhan Indonesia III (Persero) Surabaya). Jurnal Administrasi Bisnis, 2 (2), hal.1-6.

Berry, M. L. (2010). Predicting turnover intent: Examining the effects of employee engagement, compensation fairness, job satisfaction, and age. Doctoral dissertation. University of Tennessee, Knoxville.

Blau, P. M. (1964). Exchange and power in social life . New York: Wiley. 
Bockerman, P. and P. Ilmakunnas. (2007). Job disamenities, job satisfaction, quit intentions, and actual separations: putting the pieces together. Munich Personal RePEc Archive, 166 (16), pp.1-28.

Cao, Z., J. Chen and Y. Song .(2013). Does total rewards reduce the core employees turnover intention?.International Journal of Business Management, 8 (20), pp.65-75.

Chiang, F. F., and T. A. Birtch. (2011). Reward climate and its impact on service quality orientation and employee attitudes. International Journal of Hospitality Management, 30 (1), pp.3-9.

Cummings, G. G., T. Macgeregor., M. Davey., H. Lee., C. A. Wong., E. Lo., M. Muise and E. Stafford. (2010). Leadership styles and outcome patterns for the nursing workforce and work environment: A systematic review. International Journal of Nursing Studies, 47 (3), pp. 363-385.

Davies, R. (2001). How to boost staff retention. People Management, 7 (8), pp.54-56.

Dewi, N. K. N. C. dan M. Subudi. (2015). Pengaruh Kepemimpinan Transformasional Terhadap Kepuasan Kerja Dan Turnover Intention Pada CV. Gita Karya Persada Denpasar.E-Jurnal Manajemen Unud, 4 (12), hal.4219-4244.

Dimaculangan, E.D. and H. M. Aguiling. (2012). The effects of transformational leadership on salesperson's turnover intention. International Journal of

El-Badawy, T. A., and M. Bassiouny. (2014). Employee Engagement as a Mediator between Transformational Leadership and Intention to Quit. Journal of Management, 12 (1), pp. 37-50.

Elizabeth, S., P. D. Paramita dan L. B. Hasiholan. (2016). Pengaruh gaya kepemimpinan transformasional, kompensasi dan komunikasi terhadap kinerja karyawan dengan kepuasan kerja sebagai variabel mediasi pada laundry elephant king. Journal Of Management, 2 (2), hal.1-12.

Emery, C. R and K. J. Barker. (2007). The Effect of Transactional and Transformasional Leadership on The Organizational Commitment and Job Satisfaction of Costumer Contact Personnel. Journal of Organizational Culture, Communication and Conflict, 11 (1), pp.77-90.

Farahani, M., M. Taghadosi., and M. Behboudi. (2011). An exploration of the relationship between transformational leadership and organizational commitment: The moderating effect of emotional intelligence: Case study in Iran. International Business Research, 4 (4), pp.211-217.

Fatima, B., A. Usman and A. Naveed. (2011). Effect of Transformational Leadership on Employees' Job Satisfaction and Organizational 
Commitment in Banking Sector of Lahore (Pakistan). International Journal of Business and Social Science, 2 (18), pp.261-26

Firth, L., D. J. Mellor., K. A. Moore., and C. Loquet., (2004). How can managers reduce employee intention to quit?.Journal of Managerial Psychology, 19 (2), pp.170-187.

Gibson, J. L., J. M. Ivancevich and Jr. J. H. Donnelly. (2008). A Diagnostic to Organizational Behavior. Boston : Allyn and Bacon.

Girma, S. (2016). The relationship between leadership style, job satisfaction and culture of the organization. International Journal of Applied Research, 2 (4), pp.35-45.

Greiman, B. C. (2009). Transformational leadership research in agricultural education: a synthesis of the literature. Journal of Agricultural Education, 50 (4), pp.50-62.

Gul, S., B. Ahmad, S. U. Rehmahn, N. Shabir, and N. Razzaq. (2012). Leadership styles, turnover intention and the mediating role of organizational commitment. Information and Knowlage Management, 2 (7), pp.44-51.

Irawati, A. dan B. Sudarsono. (2010). Pengaruh gaya kepemimpinan terhadap kepuasan kerja, produktivitas dan kinerja Organisasi. Jurnal Studi Manajemen, 4 (1), hal.23-39.

Jauhar, J., C. S. Ting., dan N. F. A. Rahim. (2017). The Impact of Reward and Transformational Leadership on Intention to Quit of Generation Y Employees in Oil and Gas Industry: Moderating Role of Job Satisfaction. Global Business and Management Research: An International Jounal, 9 (4), pp.426-441.

Jimad, H. (2011). Kepuasan Kerja, Komitmen Organisasi, dan Intensi Turnover. Jurnal Bisnis dan Manajemen, 7 (2), hal.155-165

Kanwar, Y. P. S., A. K. Singh and A. D. Kodwani. (2012). A study of job satisfaction, organizational commitment and turnover intent among the IT and ITES sector employees. Vision-The Journal of Business Perspective, $16(1), \mathrm{pp} .27-35$.

Kreitner, R. dan A. Kinicki, (2005). Perilaku Organisasi. Jakarta: Salemba Empat.

Long C. S., L. Y. Thean., W. K. W. Ismail and A. Juson. (2012). Leadership styles and employees turnover intention: Exploratory study of academic staff in a Malaysian College. World Applied Sciences Journal, 10 (4), pp.575-581. 
Martin, A. G. Roodt. (2011). Perceptions Of Organisational Commitment. .Job Satisfaction And Turnover Intentions Un A Post Merger South African Tertiary Instution. Emperical Research, (1) 34, pp.23-31.

Mas'ud, F. (2004). Survey Diagnosis Organizational. Semarang: Badan Penerbit Universitas Diponegoro.

Mitchell, M. S., R. S. Cropanzano and D. M. Quisenberry. (2005). Social exchange theory: An interdisciplinary review. Journal of Management, 31 (6), pp.874-900.

Mohammad N., B. S. Sunuharjo dan I. Ruhana. (2016). Pengaruh Kompensasi Terhadap Kepuasan Kerja Dan Intention To Leave (Studi pada Karyawan Bank Jatim Cabang Malang). Jurnal Administrasi Bisnis (JAB), 37 (2), hal.121-127.

Munir, R. I. S., R. A. Rahman., A. M. A. Malik., and H. Ma'amor. (2012). Relationship between Transformational Leadership and Employees' Job Satisfaction among the Academic Staff. Procedia-Social and Behavioral Sciences, 65 (1), pp.885-890.

Nadiri, H. and C. Tanova. (2010). An Investigation Of The Role Of Justice In Turnover Intentions, Job Satisfaction, and Organizational Citizenship Behavior In Hospitality Industry. International Journal of Hospitality Management, 29 (1), pp.33-41.

Osabiya, B. and E. Ikenga. (2015). The Impact of Leadership Style on Employee's Performance in an Organization. Public Policy and Administration Research, 5 (1), pp.193-205.

Pamudji, S. (2009). Kepemimpinan Pemerintahan Di Indonesia. Cetakan kelima. Jakarta: Bumi Aksara.

Peachey, J. W., L. J. Burton dan J. E. Wells. (2014). Examining the Influence of Transformational Leadership, Organizational Commitment, Job Embeddedness, and Job Search Behaviors on Turnover Intentions in Intercollegiate Athletics. Leadership and Organization Development Journal, 35 (8), pp.755-740.

Purit P. (2016). Effect of transformational leadership on strategic human resource management and firm success of Toyota's dealer in Thailand. Journal of Business and Retail Management Research (JBRMR), 10 (2), pp.54-63.

Purnomo, H. dan M. Cholil. (2010). Pengaruh Gaya Kepemimpinan terhadap Kepuasan Kerja pada Karyawan Administratif di Universitas Sebelas Maret Surakarta. Jurnal Sumber Daya Manusia, 4 (1), hal.27-35.

Prihartono R.W. (2013). Komitmen Organisasi Dan Turnover Intention Pada Karyawan PT. Rentokil Initial Surabaya. Jurnal Ilmu Manajemen, 1 (3), hal.931-944 
Rahman, W. dan N. Zekeriya. (2013). Employee development and turnover intention: theory validation. European Journal of Training and Development, 37 (6), pp. 564-579.

Ridlo, I. A. (2012). Turnover Karyawan Kajian Literature. Surabaya: PH Movement Publication.

Ridwan dan E. Kuncoro. (2012). Cara Menggunakan Dan Memaknai Path Analysis. Bandung: Penerbit Aflabeta.

Robbins, S. P. (2006). Perilaku Organisasi. Jakarta: Prehallindo.

Robinson dan N. Aprilia. (2005). Pengaruh Komitmen Organisasi. Kepuasan Kerja, dan Keperilakuan Etis terhadap Keinginan Berpindah pada Profesional Bidang Teknologi Informasi. Jurnal Bisnis dan Manajemen, 5 (1), hal.23-24.

Sari, A. A. M. P. dan A. A. A. Sriathi. (2014). Pengaruh Kepemimpinan Transformational, Kompensasi Finansial Dan Komunikasi Terhadap Kepuasan Kerja Karyawan Pada Legian Village Hotel Bali. E-Jurnal Manajemen Universitas Udayana, 3 (7), hal.1983-1998.

Sartika, D. (2014). Pengaruh Kepuasan Kerja dan Gaya Kepemimpinan Transformasional terhadap Keinginan Keluar Karyawan dengan Komitmen Organisasi sebagai Variabel Mediasi (Studi Kasus di CV. Putra Tama Jaya). Management Analysis Journal, 3(2), hal. 19-30.

Shurbagi, A. M. A., and I. B. Zahari. (2012). The Relationship between Organizational Culture and Job Satisfaction in National Oil corporation of Libya. International Journal of Humanities and Applied sciences, 1 (3), pp.88-93.

Srinadi, N. N. dan 1 W. G. Supartha. (2015). Peran Mediasi Kepuasan Kerja Pada Hubungan Motivasi Kerja Dengan Intention To Quit. E-Jurnal Ekonomi dan Bisnis Universitas Udayana, 4 (3), hal.197-219.

Tjoeiyanto, F. (2010). Pengaruh Kepuasan Kerja dan Komitmen Afektif terhadap Keinginan Berpindah pada Staf Kantor Akuntan Publik di Makassar. Jurnal Adiwidia, 1 (1), hal.13-20.

Tzeng, H. M. (2002). The Influence of Nurses' working Motivation and Job Satisfaction On Intention To Quit: An Empirical Investigation In Taiwan. International Journal of Nursing Studies, 39 (8), pp.867-878.

Ucho, A., T. M. Kavga and I. E. Onyishi. (2012). Job Satisfaction, Gender, Tenure, and Turnover Intention among Civil Servants in Benue State. Interdiciplinary Journal Of Contemporary Research in Business. 3 (11), pp. 378-387.

Utama, M. S. (2016). Aplikasi Analisis Kuantitatif Untuk Ekonomi Dan Bisnis. Denpasar: CV. Sastra Utama.. 
E-Jurnal Manajemen, Vol. 8, No. 4, 2019: 2042 - 2070

Yukl, G. (2007). Kepemimpinan dalam Organisasi. Edisi Kelima. Jakarta: PT. Gramedia. 